Ecology groups combat Chinese irrigation plan

Chinese plans to divert water from the Yangtze to irrigate northern China have run into cautiously expressed but clear opposition from Chinese environmentalists. A recent meeting of the Chinese Society for Water Conservancy, officially described as an "academic discussion" on the plan, concluded that in the past, "our improper water control plans violated objective laws". Any plans to divert the Yangtze, they stressed, must be considered not from a purely engineering point of view, but should also take into account possible ecological changes produced by the scheme.

As far as the engineers are concerned, plans still remain flexible. A national forum held in Tianjin at the beginning of April discussed three possible routes: the "Western route" from the mountainous upper reaches of the Yangtze via "snaking tunnels" to north-west China; the "middle route", via a projected canal which would cross the Hwang-Ho near Zhengzhou; and the "eastern route" which would roughly follow that of the Grand Canal built by the Emperor Yang Di in about $600 \mathrm{AD}$.

All three routes, the forum decided, were practicable, although each plan still required some improvement. Construction of the western route, it was concluded, lay beyond China's capability at the moment. The eastern route, first announced in August 1978, although feasible, attracted considerably less support than the middle route, which appeared to be the choice of the Yangtze Basin Planning Commission. A spokesman for the commission told the forum that this route would involve the construction of a $1,000 \mathrm{~km}$ canal from the Banjiangkou reservoir on the Han river (a major tributary of the Yangtze), as far as Peking, via the foothills of the Funiu range and the Nanyang basin in southern Henan, approaching Peking on a route parallel to the PekingCanton railway. When completed, he said, the scheme would irrigate $4,666,000$ ha of farmland, bringing an average of 10,000 million $\mathrm{m}^{3}$ water annually to the Hai river basin, thus equalling the annual flow of the entire Hai system.

However, it might seem strange to divert water from the Yangtze across the Hwang-Ho. Why not simply irrigate north-west China with water diverted from the Hwang-Ho? The reason is that the mean flow rate of the Yangtze

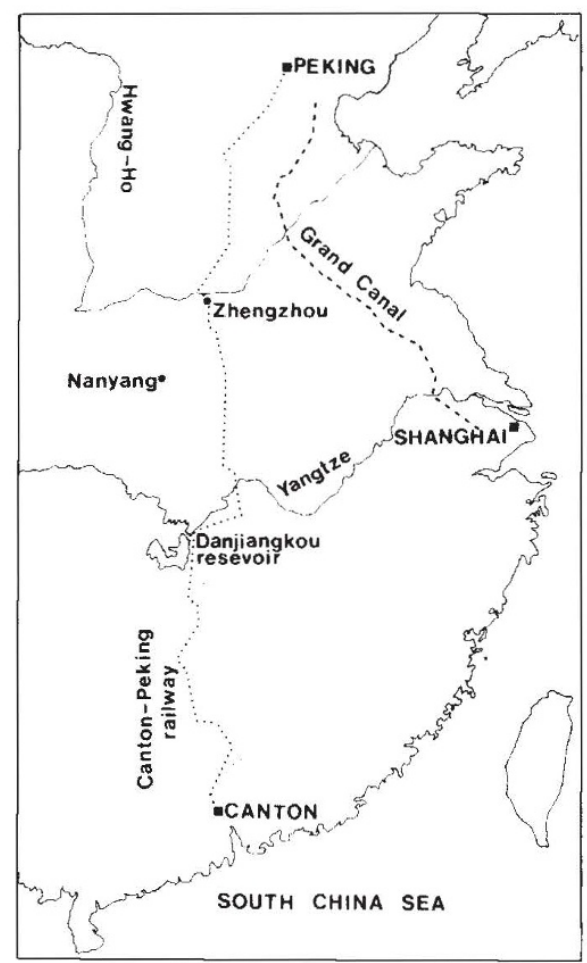

is $34,000 \mathrm{~m}^{3} \mathrm{sec}^{-1}$, considerably greater than the $1,500 \mathrm{~m}^{3} \mathrm{sec}^{-1}$ flow rate achieved on average by the Hwang-Ho.

The spokesman admitted, however, that there was one major disadvantage to this plan. The annual output of the Danjiangkou hydroelectric station would have to be reduced by anything from 700 million to 1,700 million $\mathrm{kWh}$ annually. This, however, he claimed, could be compensated by the Gezhou power station now under construction further westward.

At least one water conservancy specialist, a delegate from Qinghua University, showed some support for the plan. He noted that large areas of rock fissures and sandy structures beneath Peking city could be used as an emergency water store, while some $15,000 \mathrm{sq} \mathrm{km}$ of "abandoned river beds' north of the Hwang-Ho could be used to store $39,000 \mathrm{~m}^{3}$. In general, however, the conservationists are somewhat cautious. The "academic discussion" of the Conservancy Society pointed out a number of factors which demand further consideration. Would the diversion, they asked, cause secondary salinisation and alkalinisation of the soil? Further, what would happen in drought years? In 1978, droughts in the middle and lower Yangtze basin and the consumption of large quantities of water for irrigation led to a back-flow of sea water into the Yangtze estuary, so that, for a time, the population of Shanghai was obliged to drink brackish water, while at Chongming island, which supplies agricultural and market-garden produce to Shanghai, cultivation was seriously affected. Any proposed diversion of the Yangtze, they stress, "must conform to the law of nature and the economic law".

Vera Rich

\section{Hungarian scientists want better links with government}

Hungary's Academy of Sciences has adopted a new constitution which calls for greater accountability from government departments and industry.

Although in July 1969 the Central Committee of the Hungarian Communist Party affirmed, in a startling change of direction, the need for complete freedom in scientific research and an atmosphere of free and uninhibited discussion among scientists, economic demands, both national and within the Comecon framework, have led to a policy of closer integration between research and production. This the Hungarian scientists seemed perfectly prepared to accept. Last year's General Assembly of the Academy stressed the need for greater selectivity in research subjects, taking into account the current "social needs".

Nevertheless, this linkage does not seem to be operating as smoothly as hoped. There are considerable delays (running into years and sometimes decades) in the introduction of Hungarian patents and inventions in practice. This is not only due to bureaucratic delays; last summer, the president of the National Patent Office, Emil Tasnadi, told the prestigious political and literary journal Elet es Prodalom that the fault lay largely with the scientists. There are some 35,000 scientists in Hungary, he said, but their sole aim is to achieve academic degrees: the titles of Candidate (PhD) and Doctor bring with them, respectively, a life-long stipend of 500 and 1,000 forints per month. Since these degrees are earned throu'gh the publishing of articles and books, he said, and not by inventions, only six researchers in every thousand actually have a patent to their credit.

While not aotually answering Tasnadi directly, Dr Janos Szentagothai, the president of the Academy, took the opportunity of this year's General Assembly to state the scientists' case. Links between research and production have come closer in recent years, he noted approvingly; nevertheless, the situation is by no means satisfactory. The various departments of the Academy duly make the proper recommendations to the production sector-but receive little or no feedback. Frequently, he said, the scientists do not know if the recommendations have even been discussed.

The new constitution of the Academy, adopted by the General Assembly on 11 May, and made retroactive to last April, demands that this situation should be rectified. 